\title{
Study on the factors of industrial electricity consumption behavior in Hunan Province based on multiple regression analysis
}

\author{
Ming Wen ${ }^{1,2}$, Yun Zhang ${ }^{1,2}$, Zhen $\mathrm{Jia}^{3,{ }^{*}}$, and Xingwen $\mathrm{Tu}^{3}$ \\ ${ }^{1}$ Hunan Key Laboratory of Energy Internet Supply-demand and Operation, 410004 Changsha, China \\ ${ }^{2}$ State Grid Hunan Electric Power Company Limited Economic \& Technical Research Institute, \\ 410004 Changsha, China \\ ${ }^{3}$ Hunan University, School of Economics and Trade, 410079 Changsha, China
}

\begin{abstract}
In recent years, Hunan province has gradually accelerated the adjustment of industrial structure, and has achieved a rapid industrial growth, thereupon the total amount of industrial electricity has increased greatly. There is an internal correlation between the industrial growth and electricity consumption. Therefore, based on this background, this paper established multiple linear regression models to study the influencing factors on the electricity consumption behavior of the three industries with the most electricity consumption in Hunan Province. The regression results show that the iron and steel output, raw coal price index and Mylpic mine price index can significantly affect the electricity consumption of ferrous metal industry. Cement output, cement price and real estate development investment can significantly affect the electricity consumption of non-metal industry. Automobile output, integrated circuit output and per capita disposable monthly income can significantly affect the electricity consumption of transportation and electrical and electronic equipment manufacturing industry in Hunan Province.
\end{abstract}

\section{Introduction}

As we all know, electricity consumption, as the "barometer" of economic development, plays a decisive role for the entire national economy (Shiu et al., 2004 ${ }^{[1]}$; Tang et al., 2013 ${ }^{[2]}$; Zhang et al., 2017 ${ }^{[3]}$; Xia et al., 2020 $\left.{ }^{[4]}\right)$. As industry is the pioneer of national economic development, the relationship between industrial electricity consumption and national

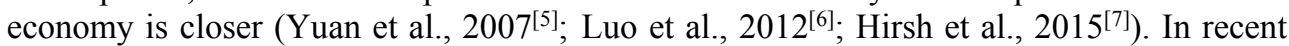
years, Hunan province has gradually accelerated the adjustment of industrial structure, and has achieved a rapid industrial growth, thereupon the total amount of industrial electricity has increased greatly (Jiang et al., 2012 ${ }^{[8]}$; Liu et al., 2020 ${ }^{[9]}$ ).

The industrial electricity consumption accounts for a large proportion of the total social electricity consumption, so its variation has also attracted the attention of scholars. He et al. $\left(2006 \mathrm{a}^{[10]}, 2006 \mathrm{~b}^{[11]}, 2007^{[12]}\right)$ used Granger causality test and error correction model to

\footnotetext{
* Corresponding author: qwe0jiaz@163.com
} 
analyze the two-way relationship between electricity consumption and gross domestic product (GDP) growth. Guo (2010) ${ }^{[13]}$ studied the economic electricity relationship of the ferrous metal industry in China. Ge et al. (2016) ${ }^{[14]}$ and Wang et al. (2018) ${ }^{[15]}$ investigated the relationship between Anhui's industrial electricity consumption and value added structure. In conclusion, most of previous studies were based on the characteristics of national electricity use, while less was based on the perspective of provincial electricity demand as the literature on Hunan Province is almost blank. As a complement to this, the paper took Hunan province as the research object and established multiple linear regression models to study the influencing factors on the electricity consumption behavior of the three industries with the most electricity consumption.

\section{Analysis of electricity consumption in three typical industries}

\subsection{The ferrous metal smelting and rolling processing industry}

As can be seen from Figure 1, the trend of economic development and electricity consumption of ferrous metal smelting and rolling processing industry was not completely consistent in recent years. Specially, the main products of the ferrous metal industry, steel production, fluctuated greatly from the end of 2011 to the 2012, which may be related to the proposal that the steel industry should focus on solving the problem of excess capacity during the 11th Five-Year Plan period. After that, there can be seen a gradual rose in steel production and a relative stability in electricity consumption.

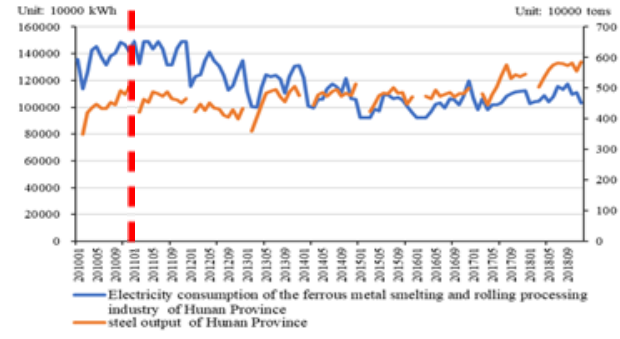

Fig. 1. Electricity consumption of the ferrous metal industry and steel output in Hunan Province.

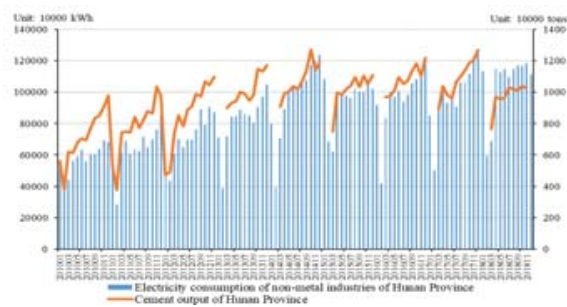

Fig. 2. Electricity consumption of the nonmetal industry and cement output in Hunan Province.

\subsection{The non-metallic mineral products industry}

Figure 2 showed the trend of cement production and electricity consumption of non-metal industries in Hunan Province from 2010 to 2018 was generally similar, but there were some differences. From the monthly data of each year, both of them showed a trend of gradual rise. From the annual data, both cement production and electricity consumption in the non-metal industry showed a turning point in 2015, that is, it did not increase but declined, which was mainly affected by the lack of industrial product market demand at that time, leading to the slowdown of both production and sales growth of the industry products.

\subsection{The transportation and electronic equipment manufacturing industry}

As can be seen from Figure 3, the overall electricity consumption of this industry was on the rise. However, the annual electricity consumption fluctuated greatly, possibly because the industry's electricity consumption had a great relationship with the seasons. As a whole, there 
was a big drop in February every year, as factories are closed during the Lunar New Year holiday. Also, the electricity consumption in October showed a significant decline, because the industrial load of domestic decreases in October every year and there was a slight increase of electricity consumption in July and August every year due to the hot weather.

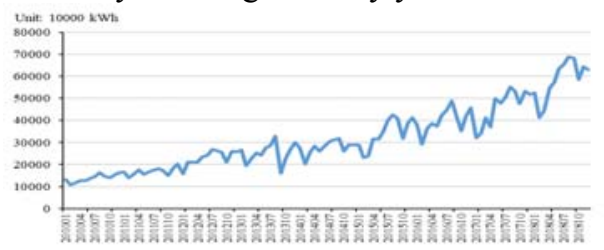

Fig. 3. Electricity consumption of transportation, electrical and electronic equipment manufacturing industry in Hunan Province. All variable data in Figs(1-3) were obtained from the Wind database.

\section{Model and empirical results}

Stepwise regression model, as one of the multiple regression analysis methods, is to establish the optimal regression model by gradually introducing the research variables. In this paper, a stepwise regression model was established to explore the relationship between the electricity consumption and its main influencing factors. The data selected in the model were the monthly data of Hunan Province from January 2010 to December 2018. All explanatory variable data were obtained from the Wind database. This study established the multiple linear regression models between the electricity consumption of three key industries and its main explanatory variables as follows:

$$
\begin{gathered}
\ln \text { Elec }_{1}=\alpha+\beta_{1} \ln \text { output }+\beta_{2} p m i+\beta_{3} \ln i n v+\beta_{4} \text { index }+\beta_{5} \text { mylpic } \\
\ln \text { Elec }_{2}=\alpha+\beta_{1} \text { ceoutput }+\beta_{2} \text { cep }+\beta_{3} s c i+\beta_{4} i n v \\
\ln \text { Elec }_{3}=\alpha+\beta_{1} \ln \text { auto }+\beta_{2} \ln c i r+\beta_{3} \ln p c d i+\beta_{4} p m i
\end{gathered}
$$

Among them, Elec , Elec $_{2}$, Elec $_{3}$ respectively represent the electricity consumption of ferrous metal smelting and rolling processing industry, non-metallic mineral products industry, and transportation and electrical and electronic equipment manufacturing industry (unit: 10,000 kWh). output represents the iron and steel output (unit: ten thousand tons); pmi represents the Purchasing Managers' Index (PMI Composite Index) of the steel industry; inv represents the investment amount of real estate development (unit: 100 million yuan); index is the raw coal price index; mylpic is the mine price index of Mylpic; ceoutput denotes cement output (unit: ten thousand tons); $c e p$ denotes cement price (unit: yuan/ton); sci represents the climate index of non-metallic mineral products industry; auto denotes automobile output (unit: ten thousand tons); $c i r$ is integrated circuit output (unit: ten thousand); pcdi represents per capita disposable income (unit: yuan). Based on the above models and research data, the stepwise regression results were shown in Table 1-3.

Table 1 showed the regression results for ferrous metal industry. Explanatory variables were added successively from Model 1 to Model 4, and the goodness of fit $\mathrm{R}^{2}$ increased gradually, indicating that the model was improving. In Model 4, $\mathrm{R}^{2}$ reached 0.779 , which meant that $77.9 \%$ of the fluctuation in the power consumption of ferrous metal industry can be explained by the model. In terms of each coefficient in model 4, from the point of statistical significance, output, index and mylpic were significant under the significance level of 0.1 and 0.01 , showing that there was a close correlation between the three and the electricity 
consumption of ferrous metal industry. But $p m i$ and $i n v$ failed to pass the T test. From the economic sense, in the case of the other variables unchanged, a $1 \%$ increase of output would result in a $0.244 \%$ increase of Elec 1 . Every $1 \%$ increase of index would lead to a $0.273 \%$ increase of Elec 1 . Each 1\% increase of mylpic would increase Elec f $_{1}$ by $0.247 \%$.

Table 1. Regression Results of Electricity Consumption in Ferrous Metal Industry.

\begin{tabular}{|c|c|c|c|c|}
\hline Variables & Model1 & Model2 & $\begin{array}{l}\text { Model3 } \\
\text { Elec }_{1}\end{array}$ & Model4 \\
\hline output & $\begin{array}{l}-0.243 \\
(0.148)\end{array}$ & $\begin{array}{l}-0.265^{*} \\
(0.147)\end{array}$ & $\begin{array}{l}0.0889 \\
(0.150)\end{array}$ & $\begin{array}{l}0.244^{*} \\
(0.126)\end{array}$ \\
\hline pmi & & $\begin{array}{l}0.00574 * \\
(0.00302)\end{array}$ & $\begin{array}{l}-0.00255 \\
(0.00234)\end{array}$ & $\begin{array}{l}-0.00319 \\
(0.00193)\end{array}$ \\
\hline$i n v$ & & & $\begin{array}{l}-0.101 * * \\
(0.0425)\end{array}$ & $\begin{array}{c}0.0261 \\
(0.0402)\end{array}$ \\
\hline index & & & $\begin{array}{c}0.670 * * * \\
(0.0694)\end{array}$ & $\begin{array}{c}0.273 * * * \\
(0.0842)\end{array}$ \\
\hline mylpic & & & & $\begin{array}{c}0.00247 * * * \\
(0.000384)\end{array}$ \\
\hline $\mathrm{R}^{2}$ & 0.028 & 0.065 & 0.670 & 0.779 \\
\hline
\end{tabular}

Note: The parentheses are standard errors. $* * * * *$ and $*$ indicate significant at the significance level of $0.01,0.05$ and 0.1 , respectively. Same as below.

The regression results of non-metallic mineral products industry were shown in Table 2. In Model 4, the $\mathrm{R}^{2}$ reached 0.673 , which meant that $67.3 \%$ of the fluctuation in the electricity consumption of this industry can be explained by the model. As for the coefficients in Model 4, ceoutput, inv and cep were statistically significant at the significance level of $0.01,0.05$ and 0.1 , respectively. However, $s c i$ failed to pass the t-test. From an economic point of view, holding other variables constant, an increase of one unit ceoutput would result in an increase of 72.38 unit $E l e c_{2}$. An increase of one unit cep would result in an increase of 50.89 unit $E l e c_{2}$. The increase of one unit inv would result in an increase of 61.61 unit Elec .

Table 2. Regression Results of Electricity Consumption in Nonmetallic Mineral Products Industry.

\begin{tabular}{ccccc}
\hline Variables & Model1 & Model2 & Model3 & Model4 \\
& & & Elec $_{2}$ & \\
\hline \multirow{2}{*}{ ceoutput } & $103.4^{* * *}$ & $89.53^{* * *}$ & $85.22^{* * *}$ & $72.38^{* * *}$ \\
& $(5.783)$ & $(10.76)$ & $(12.71)$ & $(12.81)$ \\
cep & & $85.37^{* * *}$ & $88.29^{* * *}$ & $50.89^{*}$ \\
& & $(17.78)$ & $(25.55)$ & $(29.05)$ \\
sci & & -141.5 & -166.9 \\
& & $(192.2)$ & $(181.5)$ \\
inv & & & $61.61^{* *}$ \\
$\mathrm{R}^{2}$ & & & & $(25.54)$ \\
\hline
\end{tabular}

The regression results of transportation and electrical and electronic equipment manufacturing were shown in Table 3. With the gradual inclusion of explanatory variables, the coefficient values of most variables did not change much and were always significant at the significance level of 0.01 , and $\mathrm{R}^{2}$ increased to 0.852 . For each explanatory variable, as the main products of this industry, auto and cir were statistically highly significant. When auto and cir increased by $1 \%$, Elec 3 increased by $0.154 \%$ and $0.057 \%$ respectively. pcdi was also significant at the significance level of 0.01 . When pcdi increased by $1 \%$, Elec 3 increased by $0.753 \%$. 
Table 3. Regression Results of Electricity Consumption in Transportation and Electrical and Electronic Equipment Manufacturing Industry.

\begin{tabular}{ccccc}
\hline \multirow{2}{*}{ Variables } & Model1 & Model2 & Model3 & Model4 \\
& & \multicolumn{3}{c}{ Elec $_{3}$} \\
\hline \multirow{2}{*}{ auto } & $0.643^{* * *}$ & $0.303^{* * *}$ & $0.146^{* * *}$ & $0.154^{* * *}$ \\
& $(0.0569)$ & $(0.0594)$ & $(0.0548)$ & $(0.0556)$ \\
cir & & $0.0811^{* * *}$ & $0.0598^{* * *}$ & $0.0571^{* * *}$ \\
& & $(0.0102)$ & $(0.00917)$ & $(0.00896)$ \\
pcdi & & $0.774^{* * *}$ & $0.753^{* * *}$ \\
& & & $(0.145)$ & $(0.151)$ \\
pmi & & & & 0.0152 \\
$\mathrm{R}^{2}$ & 0.580 & 0.736 & $0.0106)$ \\
\hline
\end{tabular}

\section{Conclusion}

This paper used multiple linear regression analysis models to explore the internal and external factors affecting industrial electricity consumption in Hunan Province. The regression results showed the iron and steel output, raw coal price index and Mylpic mine price index can significantly affect the electricity consumption of ferrous metal industry. Cement output, cement price and real estate development investment can significantly affect the electricity consumption of non-metal industry. Automobile output, integrated circuit output and per capita disposable monthly income can significantly affect the electricity consumption of transportation and electrical and electronic equipment manufacturing industry in Hunan Province. In addition, the models also can be used to forecast the short-term direction of electricity consumption in corresponding industries of Hunan province.

\section{References}

1. A. Shiu, P. L. Lam, Energy Policy, 32(2004).

2. C. F. Tang, E. C. Tan, Applied Energy, 4, 104(2013).

3. C. Zhang, K. Zhou, S. Yang, et al., Renewable \& Sustainable Energy Reviews, 76(2017).

4. L. Xia, W. He, IOP Conference Series Earth and Environmental Science, 571(2020).

5. J. Yuan, C. Zhao, S. Yu, et al., Energy Economics, 6, 29(2007).

6. H. Luo, L. V. Lianhong, B. Zhang, Frontiers in Energy, 4, 6(2012).

7. R. F. Hirsh, J. G. Koomey, The Electricity Journal, 9, 28(2015).

8. Y. S. Jiang, N. P. Li, X. Q.Wei, et al., Key Engineering Materials, 517(2012).

9. X. Liu, T. Sun, Q. Feng, et al., Energy, 196(2020).

10. Y. X. He, S. H. Zhao, et al, Journal of Industrial Technological Econ omics, 25(2006a).

11. Y. X. He, X. J. Chai, S. H. Zhao, et al., Journal of North China Electric Power University (Natural Science Edition), 33(2006b).

12. Y. X. He, J. J. Wei, Q. Cai, et al., North China Electric Power, 4(2007).

13. L. J. Guo, North China Electric Power, 11(2010).

14. F. Ge, B. Wang, C. Chen, Z. Li, Journal of West Anhui University, 31(2016).

15. B. Wang, M. Yang, Z. Li, S. N. Xing, B. H. Xu, Electric Power, 51(2018). 